\title{
THE AUSCULTATORY FINDINGS IN HYPERTENSION
}

\author{
BY \\ JOHN BARLOW* AND PRISCILLA KINCAID-SMITH \\ From the Department of Medicine, Postgraduate Medical School of London \\ Received July 28, 1959
}

In order to determine the incidence and significance of the various auscultatory findings in hypertension, a clinical and phonocardiographic study was carried out in 100 patients. The patients were observed over 18 months to two years, and the necropsy findings in those who died have been correlated with the clinical signs.

\section{Methods}

The patients had average casual blood pressure readings of over $180 \mathrm{~mm}$. $\mathrm{Hg}$; 69 per cent were out-patients and 31 per cent in-patients. Following the classification of Keith et al. (1939), 20 per cent were Grade I, 41 per cent Grade II, 16 per cent Grade III, and 23 per cent Grade IV. Eighty per cent showed both electrocardiographic and radiological evidence of left ventricular hypertrophy, 18 per cent showed radiological but no electrocardiographic abnormality, and 2 per cent showed left ventricular hypertrophy on the electrocardiogram but not on the X-ray. Thus the study represents the findings in moderately severe hypertension.

The clinical examination was carried out by each of us within the same hour and the findings were recorded independently and subsequently compared. The only physical sign on which we frequently differed was concerning the atrial sound: this problem is discussed fully in the text. Where there was disagreement over other signs a re-examination or phonocardiogram decided the issue.

Phonocardiograms were performed with an apparatus with frequency response specifications similar to those recommended by Leatham (1952) for clinical work. Standard lead II was employed throughout for the simultaneous electrocardiogram. In cases where summation confused the interpretation of added sounds, it was usually possible to determine their origin, either by slowing the heart with carotid sinus pressure or by serial phonocardiography after clinical improvement.

\section{RESULTS}

The Atrial Sound. Audible sounds occurring 0.07 second or later after the beginning of the P wave, but preceding the beginning of the QRS complex of the simultaneous electrocardiogram, were accepted as atrial sounds. Care was taken to exclude third heart sounds which may be constantly presystolic in timing if they occur relatively late and there is a moderate tachycardia. The interpretation of a phonocardiogram in terms of audibility of any vibration may be difficult, but with any given recording system it is usually possible to distinguish between the comparatively higher-frequency audible atrial sound and the low-frequency presystolic vibrations that may occur normally and precede the main audible component of the atrial sound when this is present in a pathological heart.

The true incidence of atrial sounds is difficult to assess. Clinically it may be impossible to distinguish an atrial sound from a "split" first heart sound in which the initial component is low pitched (Kincaid-Smith and Barlow, 1959 a). We have shown that with clinical improvement the

* Present address: Department of Medicine, Witwatersrand University, Johannesburg, South Africa. 
atrial sound may become incorporated into the first heart sound and that its time relationship to the start of the QRS complex may vary in the same patient over a short period of observation (Kincaid-Smith and Barlow, 1959 b). If the atrial sound is defined as a sound preceding Q (Weitzman, 1955), then when it occurs after $Q$ it becomes an atrial component of the first heart sound (Kincaid-Smith and Barlow, 1959 a). It is impossible on clinical auscultation to distinguish such fine differences in the timing of the sound and thus a late atrial sound is indistinguishable from an atrial component of the first sound. An obvious presystolic gallop, where the atrial sound and first sound are widely separated, presents no difficulty.

On clinical auscultation both observers were agreed that an unequivocal atrial sound was present in half of the cases. Phonocardiograms were performed in 45 of these and all but one showed a large presystolic vibration representing the audible atrial sound (Fig. 1). In the one exception the sound occurred just after the $\mathrm{Q}$ and so had to be interpreted as an atrial component of the first heart sound.

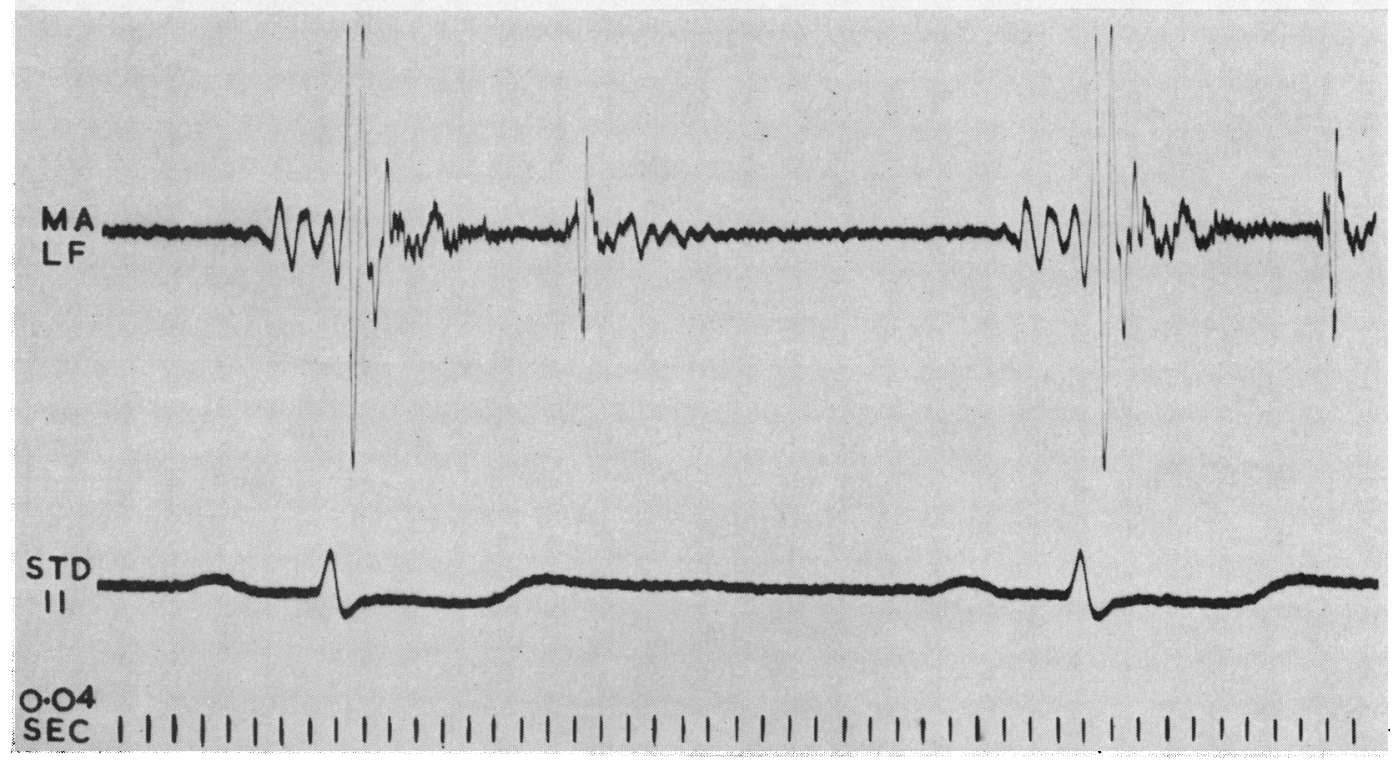

FIG. 1.-Synchronous phonocardiogram and electrocardiogram, showing atrial sound. M.A.=Mitral Area, L.F. $=$ Low Frequency.

Of the other 50 cases, three had atrial fibrillation, two had summation sounds which we were unable to elucidate with carotid sinus pressure, and in 9 both observers agreed that no atrial sound was present and this was confirmed by phonocardiography. The remaining 36 patients belonged to the difficult group in which a low-pitched sound preceded the major components of the first sound but the two were so close that it was not possible to decide clinically if a "late" atrial sound or an atrial component of the first sound were present. We have shown that in any one such case the timing of the atrial vibration varies in relation to the commencement of the QRS complex (KincaidSmith and Barlow, $1959 \mathrm{~b}$ ) and thus a phonocardiogram is only of confirmatory value when performed at the time of the clinical examination. This was done in six instances and all showed an atrial sound just preceding the start of the QRS complex.

Therefore the incidence of atrial sounds in this series was at least 50 per cent, but probably about 70 per cent. Owing to spontaneous variations, however, it is impossible to give a precise estimate of the incidence of the atrial sound.

The optimum site for audibility of the atrial sound was the apical region in all but two cases. In one of these it was best heard at the left sternal edge in the fourth interspace and in the other it was 
heard only in a localized area above the left nipple. In 30 of the 50 patients in whom a certain atrial sound was thought to be present, one or both observers considered that the sound was heard best or heard only with the patient lying on the left side. A palpable presystolic impulse was present in 38 per cent of the total series. Though sometimes more easily felt than heard, the atrial sound was palpable but not audible in only one instance.

The interval between the beginning of the $P$ wave and the atrial sound, which Duchosal (1935) termed the P-G interval, varied between 0.09 and 0.19 sec. in this series; the average was 0.145 sec. This interval altered with the clinical state of the patient and as a result of various manœuvres (Kincaid-Smith and Barlow, 1959 b).

The Third Heart Sound. Like many previous authors (Thayer, 1908 and 1909; Bridgman, 1915; Wolferth and Margolies, 1933; Braun-Menendez, 1938; Evans, 1943) we have not been able to find any criterion that distinguishes a physiological from a pathological third heart sound. We consider that this sound is usually loudest at the apex and, like the atrial sound, often audible only with the patient in the left lateral position. Because of its common occurrence in normal young subjects (Thayer, 1908 and 1909; Evans, 1943), it is essential to consider age when studying the significance of the third heart sound in hypertension. Evans (1943) states that the third heart sound does not occur in normal people over the age of 40 years.

In our series third heart sounds were heard in 34 of the 100 patients examined. Seven of these were under 40 years of age, five had had recent paroxysmal nocturnal dyspnœa or congestive cardiac failure, eight had malignant hypertension, and five had associated ischæmic heart disease. In the remaining nine it was not possible to correlate the presence of a third sound with any other common feature. All nine had electrocardiographic and radiological evidence of left ventricular enlargement in common with 80 per cent of the total series. In six of these nine the third sound was transient.

In only one patient in sinus rhythm was a third heart sound present in the absence of an atrial sound. In this instance the $\mathbf{P}-\mathbf{R}$ interval was only $0.10 \mathrm{sec}$. and this may preclude the occurrence of a presystolic atrial sound (Kincaid-Smith and Barlow, $1959 \mathrm{~b}$ ). In two patients there was atrial fibrillation so the atrial sound was obviously absent. The remaining 31 patients all had a quadruple rhythm. The third heart sound was clearly demonstrated in all 16 on whom a phonocardiogram was performed to confirm the clinical observation.

Systolic Murmurs. Systolic murmurs were present in 73 patients. According to Leatham's $(1951,1952$, and 1958) criteria these were ejection in character in 71 and regurgitant in 2 cases.

Of the ejection systolic murmurs, 39 were Grade I in intensity (Levine, 1933), 22 Grade II, 8 Grade III, and 2 Grade IV. Thirty-three were audible only at the apex and 38 at both apex and base; none was heard solely at the base. Phonocardiograms were performed in 40 of the 71 and the ejection character of the murmurs confirmed (Fig. 2). In all 48 patients on whom the test was performed, the inhalation of amyl nitrite increased the intensity of the ejection systolic murmurs (Kahler, 1932; Barlow and Shillingford, 1958; and Bruns and Van der Hauwaert, 1958).

Seven of the 71 patients with ejection systolic murmurs died during the period of observation. In six of these the aortic valve showed no evidence of calcification of the bases of the cusps nor any other abnormality. Two had had a Grade III, three a Grade II, and one a Grade I ejection murmur clinically. In the seventh patient (Grade III systolic murmur clinically) a chronic rheumatic aortic stenosis was found at autopsy. This suggests that in many cases of hypertension, even where a Grade II or III ejection systolic murmur is noted, there is often no organic lesion of the aortic valve.

A regurgitant systolic murmur was present in only two patients; this was confirmed in each case by the presence of a pansystolic murmur on the phonocardiogram and by the diminution of the murmur immediately after the inhalation of amyl nitrite (Barlow and Shillingford, 1958). One patient has since died and rheumatic mitral regurgitation was demonstrated at autopsy (Case 1 in Table I). The other (Case 2 in Table I) had associated early diastolic and mid diastolic murmurs and was therefore likely to have rheumatic heart disease. 


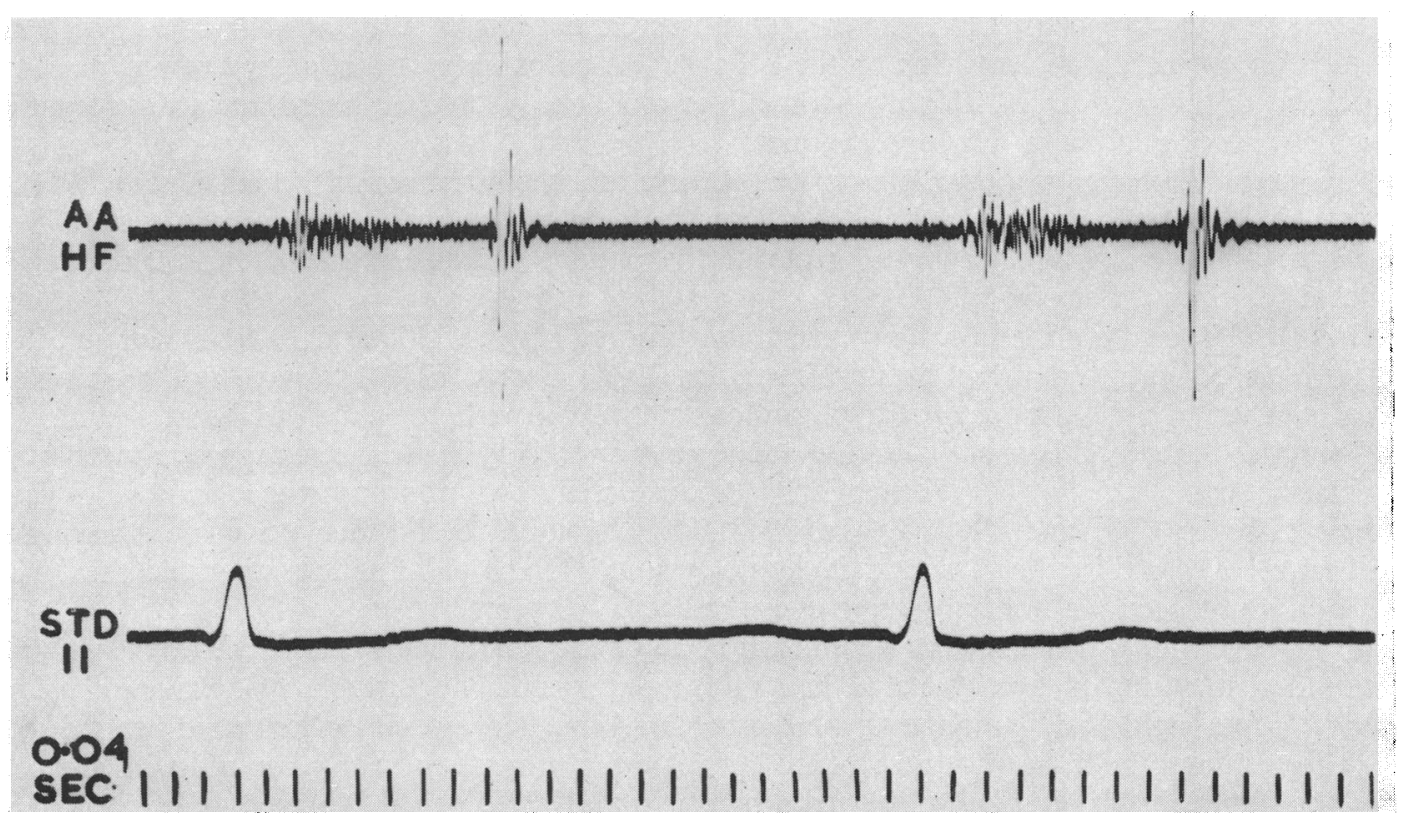

FIG. 2.-Ejection systolic murmur (Grade 2 clinically) in a hypertensive patient. A.A.=Aortic Area, H.F. $=$ High Frequency.

TABLE I

Data on Patients with Apical Regurgitant Systolic Murmurs

\begin{tabular}{|c|c|c|c|c|c|c|c|}
\hline Patient & Sex & Age & $\begin{array}{l}\text { Associated } \\
\text { murmurs }\end{array}$ & X-ray & Autopsy & Remarks & Conclusion \\
\hline 1. & F & 59 & MDM & $\mathrm{LA}+$ & Rheumatic & Aur. fib. & Organic M.R. \\
\hline 2. & $\mathbf{M}$ & 73 & MDM, EDM & LA normal & - & $\mathrm{LA}+$ on E.C.G. & Probable \\
\hline 3. & $\mathbf{F}$ & 53 & MDM & LAt & Rheumatic & - & Organic M.R. \\
\hline 4. & $\mathbf{F}$ & 33 & MDM & LAt & Libman Sacks & - & Organic M.R. \\
\hline 5. & $\mathbf{M}$ & 79 & - & $\begin{array}{c}\text { LA+ } \\
\text { calcified }\end{array}$ & $\begin{array}{l}\text { Calcified } \\
\text { posterior }\end{array}$ & - & Organic M.R. \\
\hline 6. & $\mathbf{M}$ & 42 & EDM & $\begin{array}{c}\text { mitral valve } \\
\text { LA+ }\end{array}$ & $\stackrel{\text { cusp }}{-}$ & $\begin{array}{l}\text { History of } \\
\text { rheumatic fever }\end{array}$ & $\begin{array}{c}\text { Probable } \\
\text { organic M.R. }\end{array}$ \\
\hline 7. & $\mathbf{M}$ & 81 & MDM & $\begin{array}{l}\text { LA normal } \\
\text { calcified } \\
\text { mitral and } \\
\text { aortic valves }\end{array}$ & - & - & $\begin{array}{l}\text { Probable } \\
\text { organic M.R. }\end{array}$ \\
\hline 8. & $\mathbf{M}$ & 75 & - & LA normal & - & $\begin{array}{l}\text { LA+ on E.C.G. } \\
\text { Pan S.M. for } \\
2 \text { years }\end{array}$ & $\begin{array}{c}\text { Possible } \\
\text { organic M.R. }\end{array}$ \\
\hline 9. & $\mathbf{F}$ & 60 & - & LA normal & $\begin{array}{l}\text { Mitral valve } \\
\text { normal }\end{array}$ & $\begin{array}{l}\text { Pan S.M. for } \\
3 \text { days before } \\
\text { death }\end{array}$ & Functional M.R. \\
\hline
\end{tabular}


Since functional mitral regurgitation has often been mentioned as the cause of the apical systolic murmur in hypertension (White, 1944; Fishberg, 1954; Friedberg, 1956; Levine, 1958) and because only two in our series of 100 consecutive cases had regurgitant systolic murmurs, we include observations on further patients, approximately 300 , whom we have seen presenting with hypertension over a two-year period. Seven of these had apical regurgitant systolic murmurs and this was confirmed by phonocardiography in each instance. The references to cases set out below relate to Table I. In 6 of the 7 patients we found evidence of an organic mitral valve lesion. Three of these died during the period of observation and all had organic mitral regurgitation at necropsy. One (Case 3) had chronic rheumatic mitral valve disease, another (Case 4) had Libman Sacks endocarditis associated with systemic lupus erythematosus (Fig. 3), and the third (Case 5) a calcified and distorted mitral cusp (Fig. 4) such as occurs in association with other calcified atherosclerotic lesions in old

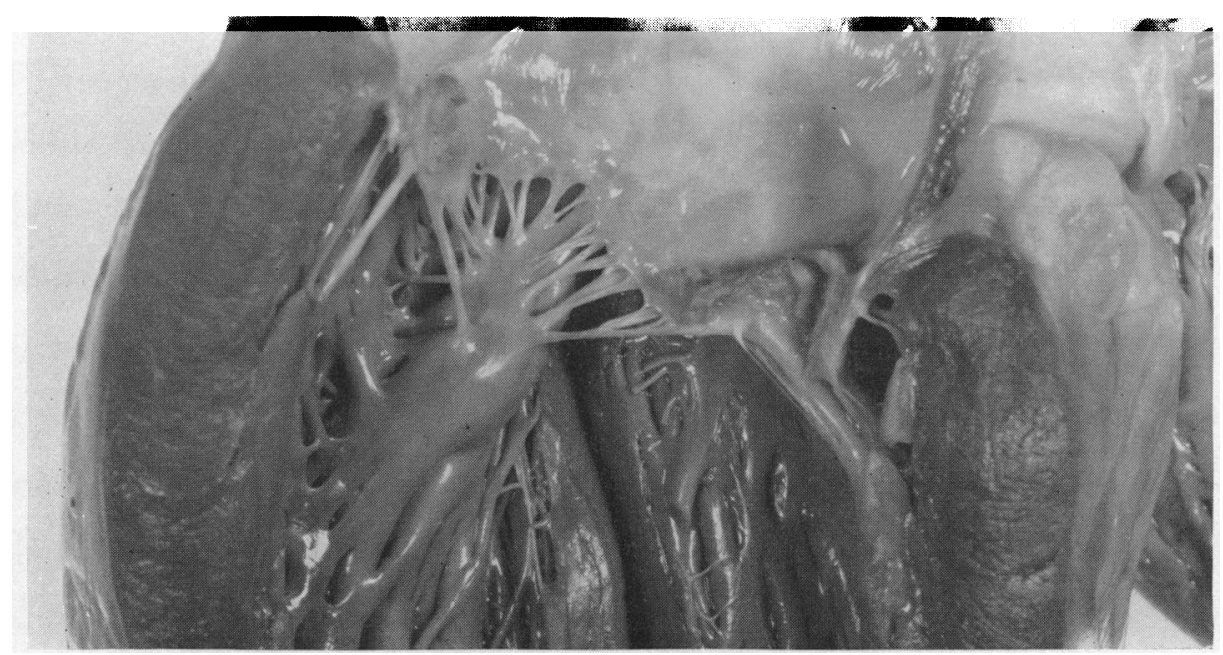

FIG. 3.-The left ventricle opened, showing chronic mitral valve scarring and Libman Sacks endocarditis (Patient 4 in Table I). Full scale.

age (Fertman and Wolff, 1946; Rytand, 1946; Rytand and Lipsitch, 1946; Fishberg, 1954; Simon and Liu, 1954). In two patients there was strong clinical evidence of organic mitral disease, a history of rheumatic fever and associated aortic regurgitation in one (Case 6), and mitral and aortic valve calcification in the X-ray of the other (Case 7). In another (Case 8) the regurgitant systolic murmur had persisted for two years and the electrocardiogram suggested left atrial hypertrophy: there was no other evidence of an organic valve lesion in this patient but in view of his age (75 years) and the rarity of functional mitral regurgitation we considered that he might well have atherosclerosis and calcification of the posterior cusp of the mitral valve. The final case (Case 9) probably had functional mitral regurgitation. This patient who was suffering from malignant hypertension developed a soft apical pansystolic murmur three days before death from uræmia and the mitral valve was normal at necropsy.

Mid-Diastolic Murmurs. The occurrence of a low pitched rumbling apical mid-diastolic murmur in hypertensive patients has long been recognized in the absence of organic mitral stenosis (Fisher, 1894; Phear, 1895; Wood and White, 1923; White, 1926; Weinstein and Lev, 1942; Harrison and Wood, 1949; Luisada et al., 1955). In only a few of the cases described, however, were the murmurs noted in hypertension with completely normal mitral valves at necropsy (Harrison and Wood, 1949; Luisada et al., 1955). Most of the remainder showed minimal organic mitral valve lesions such as calcification of the posterior cusp. 


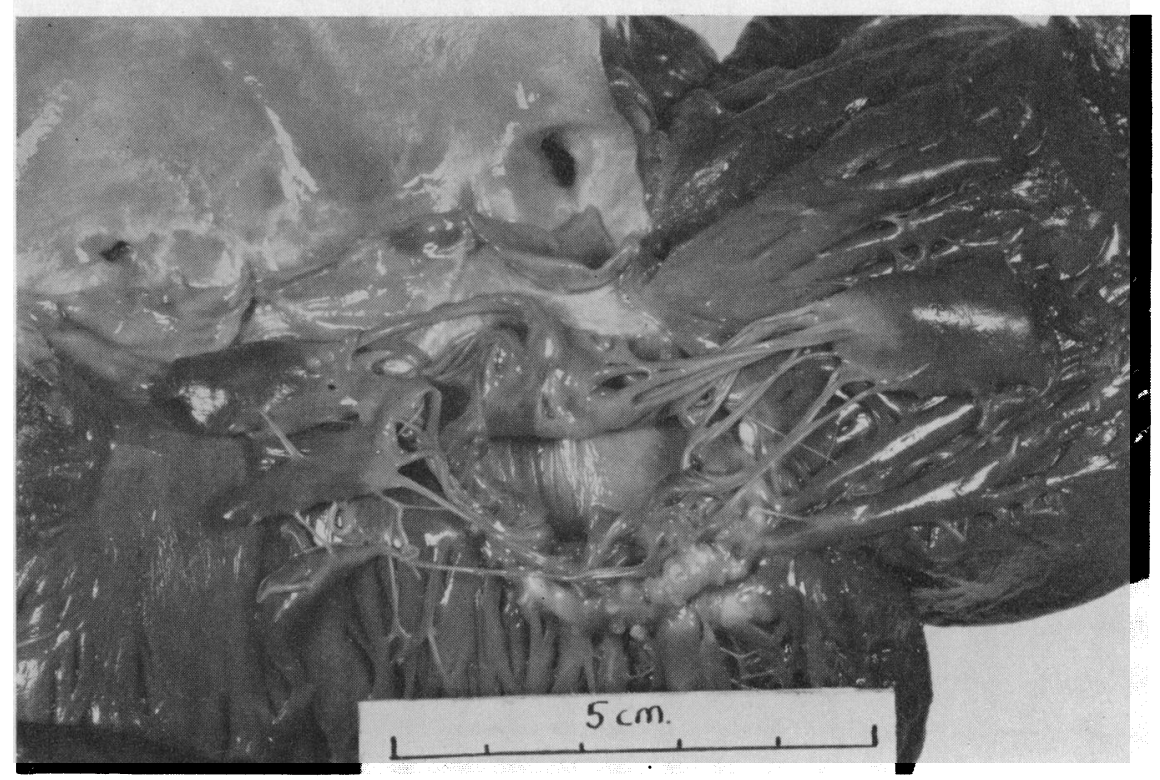

FIG. 4.-Mitral valve seen from under surface. Showing heavy calcification and scarring of posterior cusp causing organic mitral regurgitation (Patient 5 in Table I). Full scale.

In our series of 100 consecutive cases a mid-diastolic murmur was heard and recorded phonocardiographically in 6. Two of these were accepted on other criteria as probably having rheumatic heart disease; the third had systemic lupus erythematosus and possibly Libman Sacks endocarditis; the fourth (aged 80) had calcification of the mitral and aortic valves on radioscopy. In the fifth case necropsy showed a chronic rheumatic endocarditis with mild mitral stenosis and a spherical thrombus almost filling the left atrium. In the sixth patient a soft short mid-diastolic murmur was thought to be functional because of its transient nature and of the absence of other evidence of mitral valve disease.

Excluding patients with obvious rheumatic heart disease, we have heard mid-diastolic murmurs in 8 of approximately 300 other hypertensive patients observed over a period of two years. Necropsy showed that 5 of these had organic mitral valve lesions. The underlying pathology was rheumatic in one, Libman Sacks endocarditis in another (Case 4, Table I) shown in Fig. 3, and atherosclerosis with calcification of the posterior mitral cusp in three, aged 76, 77 and 79; the last of these is shown in Fig. 4. Two patients had transient short mid-diastolic murmurs, which were shown to be functional, as normal mitral valves were found at autopsy in both instances.

The cause of the "mid-diastolic murmur" in the last case was atrial contraction occurring in early diastole, due to a first degree heart block. The $P-R$ interval was nearly $0.40 \mathrm{sec}$. and both clinically and phonocardiographically the atrial sound resembled a mid-diastolic murmur (Fig. 5). This resemblance has previously been observed by others (Rytand, 1946; and Evans, 1954).

The two added diastolic sounds in quadruple rhythm with tachycardia may also resemble a mid-diastolic murmur (Luisada and Aravanis, 1957). We have seen this in several patients but the true nature of the sign was discernible on slowing and we have therefore not included these in our observations on mid-diastolic murmurs.

Thus in our experience a mid-diastolic murmur in hypertension, excluding cases of obvious rheumatic heart disease, is still likely to be associated with an organic mitral valve lesion. The commonest condition in this series was calcification in an atheromatous posterior mitral valve cusp. We have heard only 3 mid-diastolic murmurs that we believed to be functional in 


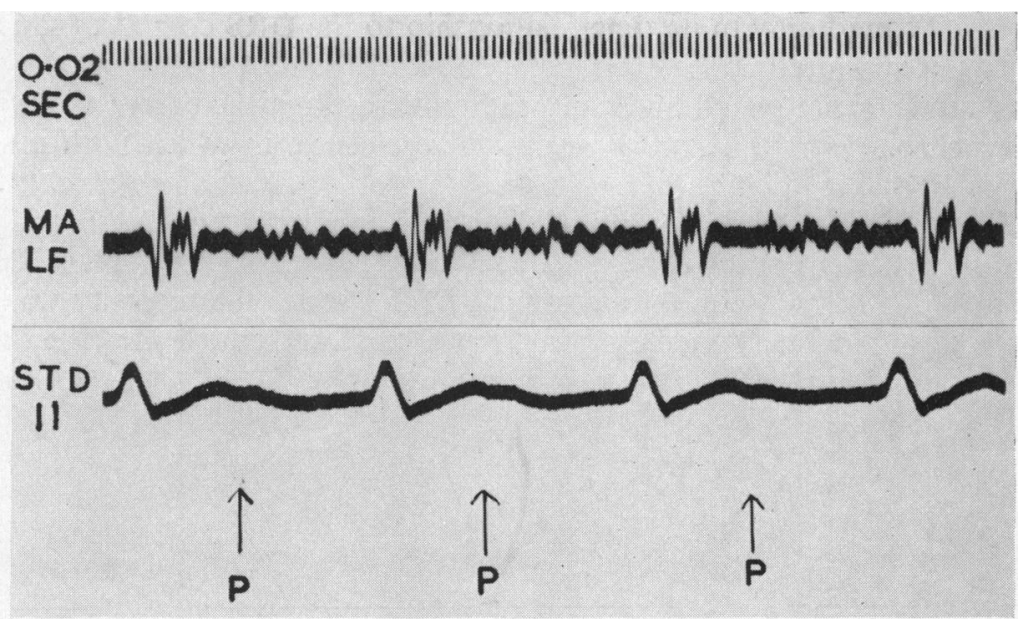

Fig. 5.-Phonocardiogram of apparent mid-diastolic murmur due to first-degree heart block ( $\mathrm{P}-\mathrm{R}$ interval about 0.40 seconds).

approximately 400 cases of hypertension; this, of course, excludes the "mid-diastolic murmurs" due to quadruple rhythm with tachycardia and the patient with the prolonged $\mathbf{P}-\mathbf{R}$ interval.

Early Diastolic Murmurs. The occurrence of an early diastolic murmur in hypertension is well documented (Boas and Fineberg, 1926; Garvin, 1940; Gouley and Sickel, 1943; White, 1944; Fishberg, 1954; Friedberg, 1956; Evans, 1957; Smirk, 1957; Levine, 1958; Wood, 1958). We encountered this murmur in 9 of the 100 patients examined. Four had malignant hypertension and three have since died; all three had normal aortic valves at autopsy. Aortic regurgitation seems to occur more commonly in severe hypertension, a Grade III or IV retinopathy being present in seven of the nine cases. The associated ejection systolic murmur was not loud in these patients and was never more than Grade II.

The early diastolic murmur in hypertension sometimes has clinical features that differ from the usual murmur of organic aortic regurgitation. It is usually a short crescendo-decrescendo murmur (Fig. 6) and may be of lower pitch than the organic murmur. It is often best heard at the apex; in all the nine patients of this series the murmur was audible at the apex and in only two was it also present at the base. We also noted variation in the duration and intensity of the murmur and in one instance it disappeared altogether after treatment with hypotensive drugs.

The First Heart Sound. The major components of the first heart sound, which are probably due to mitral and tricuspid valve closure (Leatham, 1954; Reinhold and Rudhe, 1957), were delayed in this series of hypertensive patients. As measured on low-frequency phonocardiograms in 50 cases in which there was no evidence of valvular disease, the interval between the onset of the QRS complex and the first major component of the first sound varied between 0.04 and 0.08 sec. with an average of $0.065 \mathrm{sec}$. The equivalent measurements in 25 normal subjects were 0.03 to $0.06 \mathrm{sec}$. with an average of $0.045 \mathrm{sec}$. Leonard et al. (1958) found a similar delay in the major components of the first heart sound in a study of 18 cases of atrial gallop rhythm, 17 of whom had hypertension. This delay in the first sound is one of the factors that facilitates the audibility of the atrial sound.

The intensity of the first sound varies with the timing of the atrial sound, this being independent of any change in the P-R interval or heart rate. In the same patient under standard conditions the major components of the first sound are louder when immediately preceded by an atrial vibration than they are when the atrial sound occurs early (Kincaid-Smith and Barlow, $1959 \mathrm{~b}$ ).

The common clinical impression of "splitting" of the first heart sound in hypertension is often the result of a loud atrial component of the first sound. We have shown that this atrial component 
differs from the atrial sound only in its time relationship to the QRS complex (Kincaid-Smith and Barlow, 1959 a). On auscultation the atrial component of the first sound has the same dull lowpitched character as the atrial sound and can usually be distinguished from the type of split first sound due to asynchronous mitral and tricuspid valve closure, in which both elements are high pitched.

The Second Heart Sound. The intensity of the aortic component of the second heart sound is usually increased in hypertension (Janeway, 1913; White, 1944; Fishberg, 1954; Friedberg, 1956; Evans, 1957; Wood, 1958). On clinical assessment in this series the intensity was thought to be normal in 19 per cent, moderately increased in 59 per cent, and much increased in 22 per cent.

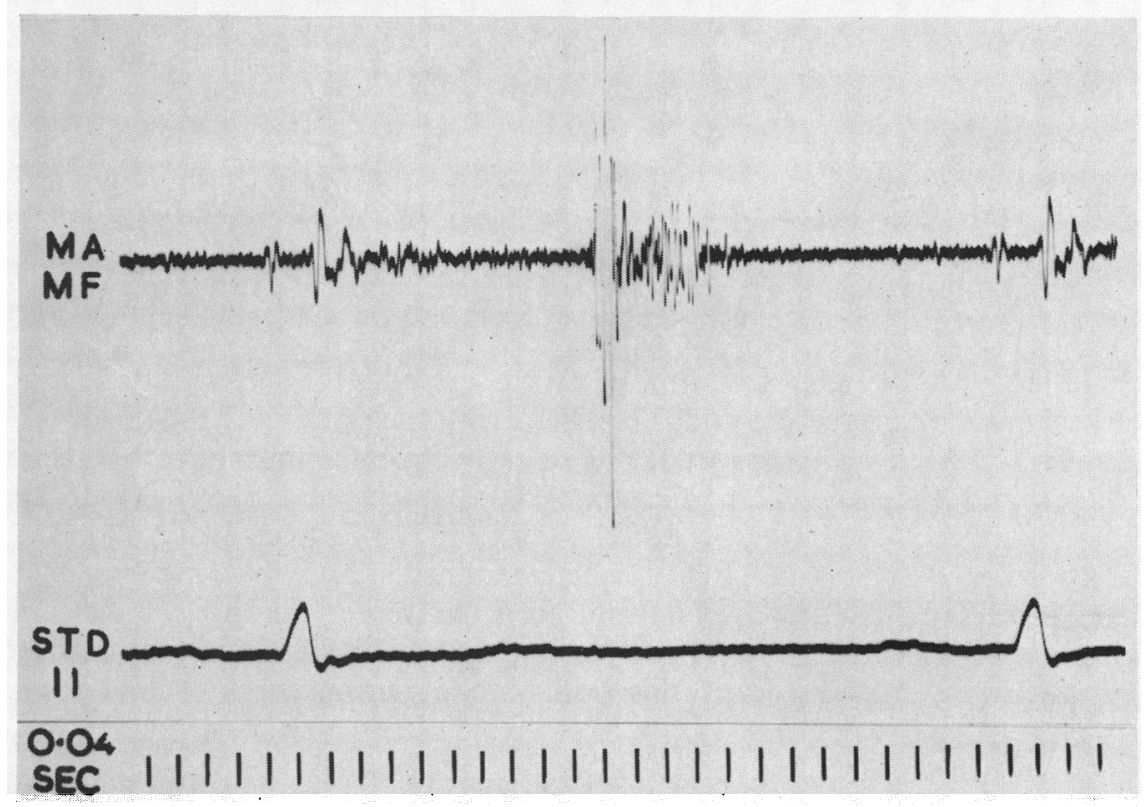

FIG. 6.-Short crescendo-decrescendo early diastolic murmur recorded in a patient with severe hypertension. M.F.=Medium Frequency.

\section{Discussion}

The Atrial Sound. The incidence of an atrial sound, at least 50 per cent and probably about 70 per cent, in our series is considerably higher than the 23 per cent recorded by Miles (1951). The severity of the hypertension in our group and the manœuvre of turning the patient on to the left side probably largely accounts for this difference. However, the difficulty in differentiating between an atrial sound and "split" first sound (Wolferth and Margolies, 1933; Duchosal, 1935; Lian, 1948; Miles, 1951) makes a clinical assessment of the incidence unreliable. Furthermore, a movement of the atrial sound towards the first heart sound may take place in a few minutes under resting conditions, and thus the cadence change from one of a triple rhythm to that of a split first heart sound (Kincaid-Smith and Barlow, 1959 (2)).

The length of the P-R interval will also influence the audibility of an atrial sound. In this series the average time of onset of the atrial sound after the beginning of the $P$ wave (P-G interval) was 0.145 second. In a patient with a $P-R$ interval of, say, 0.20 second this would give the atrial sound a presystolic position whereas in a patient with a P-R interval of 0.15 second the atrial sound would be closer to the first heart sound and the cadence would be similar to that of splitting of the first sound.

Weitzmann (1955) did not observe an atrial sound in any patient in whom there was neither radiological nor electrocardiographic evidence of left ventricular hypertrophy. Of the 18 patients in our series with radiological evidence of left ventricular enlargement but normal electrocardiograms, 12 had atrial sounds. Outside this series we detected atrial sounds in two out of six hypertensive patients with normal 
electrocardiographic and radiological appearances. These findings are in keeping with Evans' (1957) observation that an atrial sound may be present in hypertensive subjects with no evidence of left ventricular enlargement.

The Third Heart Sound. Evans (1943), Miles (1951) and Harvey and Stapleton (1958) consider that a third heart sound develops in hypertension as an accompaniment of right-sided failure. Excluding cases with recent heart failure or associated ischæmic heart disease, however, we found third heart sounds in 17 patients over the age of $\mathbf{4 0}$ years. Eight of these had malignant hypertension, a condition in which we think a third sound is common even in the absence of obvious cardiac failure. The remaining nine patients had no feature that distinguished them from the other patients in the series.

Provided the patient is in sinus rhythm, however, and the P-R interval is not unusually short, it is our experience that an atrial sound invariably develops before a third heart sound in hypertension. This presumably does not always apply in patients under the age of $\mathbf{4 0}$ where a physiological third heart sound may be present alone. But we did not see an example of this in the present series as the seven patients under the age of forty with third heart sounds all had an accompanying atrial sound and consequently a quadruple rhythm.

Systolic and Mid-Diastolic Murmurs. Our observations on approximately 400 hypertensive patients do not confirm the view (White, 1944; Fishberg, 1954; Friedberg, 1956; Levine, 1958) that functional mitral regurgitation is a common cause of an apical systolic murmur in hypertension. We have seen only one patient in whom functional mitral regurgitation seemed likely (Table I). A functional mid-diastolic murmur is also rare in our experience and we have seen this in only three instances. We believe that when an apical regurgitant systolic murmur or mid-diastolic murmur is present in a hypertensive patient there is usually organic disease of the mitral valve. Excluding cases of obvious rheumatic valvular disease, the commonest lesion in our series was atherosclerosis with calcification and deformity of the posterior mitral cusp.

Seventy-one of our original 100 patients had ejection systolic murmurs and these presumably arose at the aortic valve. Seven of these died and all but one (aged 54) had completely normal aortic valves at necropsy, suggesting that the ejection systolic murmur in hypertension is often functional. However, four of these patients were under the age of thirty-five and it is quite probable that in many older hypertensive patients the systolic murmur is associated with aortic valve sclerosis and calcification (Fishberg, 1954; Friedberg, 1956; Bruns and Van der Hauwaert, 1958).

Early Diastolic Murmur. In contrast to murmurs produced at the mitral valve, those originating at the aortic valve in hypertension are often not associated with any organic disease of the valve. We encountered the early diastolic murmur of aortic regurgitation in 9 patients, and in the 3 who died necropsy showed normal aortic valves. This suggests that the regurgitation was due to a dilated aortic ring and is in agreement with Garvin's (1940) report of 14 patients with "relative" aortic regurgitation in a study of 200 consecutive cases of hypertension at autopsy.

\section{SUMMARY}

A clinical and phonocardiographic study was performed in a hundred consecutive hypertensive patients with average casual blood pressure readings exceeding 180/100 $\mathrm{mm}$. $\mathrm{Hg}$.

An atrial sound was present in at least 50 per cent and probably about 70 per cent of the series. Spontaneous variations in the timing of the atrial sound made it impossible to give an accurate assessment of its incidence. The difficulty in differentiating between a "late" atrial sound and a "split" first heart sound is discussed. The atrial sound was palpable in 38 patients, in only one of whom was it not audible also.

A third heart sound was present in 34 patients. Provided the patient was in sinus rhythm and the $\mathbf{P}-\mathbf{R}$ interval not unduly short, it was our experience that the atrial sound invariably developed before the third heart sound. Hypertensive patients under the age of forty might have a physiological third sound.

An ejection systolic murmur was present in 71 patients. Seven of these died and the aortic valves were normal at necropsy in six.

A regurgitant systolic murmur was present in only two patients. In a total of about 400 patients we heard apical regurgitant systolic murmurs in nine, eight of whom were suspected or shown to have organic mitral regurgitation. Functional mitral regurgitation was considered the cause of the systolic murmur in only one instance.

$2 \mathrm{M}$ 
A functional mid-diastolic apical murmur was encountered in only three instances in observations on approximately 400 patients.

Excluding rheumatic valvular disease, the commonest cause of murmurs originating at the mitral valve in hypertension was atherosclerosis and calcification of the posterior mitral cusp.

Nine cases had an aortic early diastolic murmur. Three of these died and had normal aortic valves at autopsy.

The onset of the major components of the first heart sound was delayed in the 50 hypertensive patients in whom this measurement was made on phonocardiograms and compared with 25 normal controls.

On clinical assessment the aortic component of the second sound was thought to be louder than normal in 81 per cent of this series.

We wish to thank Professor J. McMichael, F.R.S., for his encouragement and advice. We are indebted to Dr. J. Shillingford for access, at all times, to the phonocardiographic apparatus.

\section{REFERENCES}

Barlow, J. B., and Shillingford, J. (1958). Brit. Heart J., 20, 162.

Boas, E. P., and Fineberg, M. H. (1926). Amer. J. med. Sci., 172, 648.

Braun-Menendez, E. (1938). Lancet, 2, 761.

Bridgman, E. W. (1915). Heart, 6, 41.

Bruns, D. L., and Van der Hauwaert, L. G. (1958). Brit. Heart J., 20, 370.

Duchosal, P. (1932). Amer. Heart J., 7, 613.

- (1935). Arch. Mal. Cour, 28, 345.

Evans, W. (1943). Brit. Heart J., 5, 205.

- (1954). Cardiography. 2nd ed., Butterworth \& Co., London.

- (1957). Lancet, 2, 53.

Fertman, M. H., and Wolff, L. (1946). Amer. Heart J., 31, 580.

Fishberg, A. M. (1954). Hypertension and Nephritis. 5th ed., Baillière, Tindall and Cox, London.

Fisher, J. (1894). Brit. med. J., 1, 906.

Friedberg, C. K. (1956). Diseases of the Heart. 2nd ed., W. B. Saunders \& Co., Philadelphia and London.

Garvin, C. F. (1940). Ann. intern. Med., 13, 1799.

Gouley, B. A., and Sickel, E. M. (1943). Amer. Heart J., 26, 24.

Harrison, C. V., and Wood, P. H. (1949). Brit. Heart J., 11, 205.

Harvey, W. P., and Stapleton, J. (1958). Circulation, 28, 1017.

Janeway, T. C. (1913). Arch. intern. Med., 12, 755.

Kahler, H. (1932). Wien. Arch. inn. Med., 23, 349.

Kincaid-Smith, P. S., and Barlow, J. B. (1959 a). Brit. Heart J., 21, 470.

(1959 b). Brit. Heart J., 21, 479.

Keith, T. B., Wagener, H. P., and Barker, N. W. (1939). Amer. J. med. Sci., 197, 332.

Leatham, A. (1951). Brit. Heart J., 13, 153.

- (1952). Brit. med. Bull., 8, 333.

- (1954). Lancet, 2, 607.

- (1958). Lancet, 2, 703.

Leonard, J. J., Weissler, A. M., and Warren, J. V. (1958). Circulation, 17, 1007.

Levine, S. A. (1933). J. Amer. med. Assoc., 101, 436.

(1958). Clinical Heart Disease. 5th ed., W. B. Saunders \& Co., Philadelphia and London.

Lian, C. (1948). Brit. Heart J., 10, 92.

Luisada, A. A., Harring, O. M., Zilli, A. B. (1955). Ann. intern. Med., $42,644$.

- , and Aravanis, C. (1957). Med. Clin. N. Amer., 41, 235.

Miles, B. E. (1951). Brit. Heart J., 13, 327.

Phear, A. G. (1895). Lancet, $2,716$.

Reinhold, J., and Rudhe, V. (1957). Brit. Heart J., 19, 473.

Rytand, D. A. (1946). Amer. Heart J., 32, 579.

, and Lipsitch, L. S. (1946). Arch. intern. Med., 78, 544.

Simon, M. A., and Liu, S. F. (1954). Amer. Heart J., 48, 497.

Smirk, F. H. (1957). High Arterial Pressure. Blackwell Scientific Pub., Oxford.

Thayer, W. S. (1908). Trans. Assoc. Amer. Phys., 23, 326.

- (1909). Trans. Assoc. Amer. Phys., 24, 71.

Weinstein, W., and Lev. M. (1942). Amer. Heart J., 23, 809.

Weitzman, D. (1955). Brit. Heart J., 17, 70.

White, P. D. (1926). Boston med. surg. J., 195, 1146.

(1944). Heart Disease. 3rd ed., The MacMillan Co., New York.

Wolferth, C. C., and Margolies A. (1933). Amer. Heart J., 8, 441.

Wood, J. E., and White, P. D. (1923). Med. Clin. N. Amer., 7, 729.

Wood, P. H. (1958). Diseases of the Heart and Circulation. 2nd ed., Eyre and Spottiswoode, London. 